\title{
Predictive Factors for Morbidity and Mortality in Patients Undergoing Laparoscopic Paraesophageal Hernia Repair: Age, ASA Score and Operation Type Influence Morbidity
}

\author{
Hannes J. Larusson · Urs Zingg • Dieter Hahnloser • \\ Karen Delport · Burkhardt Seifert · Daniel Oertli
}

Published online: 10 March 2009

(c) Société Internationale de Chirurgie 2009

\begin{abstract}
Background Patients undergoing laparoscopic paraesophageal hernia (PEH) repair risk substantial morbidity. The aim of the present study was to analyze predictive factors for postoperative morbidity and mortality.

Methods A total of 354 laparoscopic PEH repairs were analyzed from the database of the Swiss Association for Laparoscopic and Thoracoscopic Surgery (SALTS). Age $(<70$ and $\geq 70$ years) and risk (low: American Society of Anesthesiologists (ASA) scores $1+2$; high ASA scores $3+4)$ groups were defined and multivariate logistic regression was conducted.

Results In patients $\geq 70$ years of age postoperative morbidity $(24.4 \%$ versus $10.1 \% ; p=0.001)$ and mortality ( $2.4 \%$ versus $0 \% ; p=0.045)$ were significantly higher than in patients $<70$ years of age. In patients with gastropexy, this significant age difference was again present (38.8\% versus $10.5 \% ; p=0.001$ ) whereas in patients with fundoplication no difference between age groups occurred (11.9\% versus $10.1 \% ; p=0.65)$. Mortality did not differ.
\end{abstract}

H. J. Larusson and U. Zingg equally contributed as first authors.

H. J. Larusson · U. Zingg $(\bowtie) \cdot$ K. Delport · D. Oertli

Department of Surgery, University Hospital, Spitalstr. 21, 4031

Basel, Switzerland

e-mail: uzingg@uhbs.ch

H. J. Larusson

e-mail: hannesjon@gmail.com

D. Hahnloser

Department of Visceral and Transplantation Surgery,

University Hospital, Rämistr. 100, 8091 Zurich, Switzerland

B. Seifert

Biostatistics Unit, ISPM, University of Zurich,

Hirschengraben 84, 8001 Zurich, Switzerland
High-risk patients had a significantly higher morbidity (26.0\% versus $11.2 \% ; p=0.001)$ but not mortality $(2.1 \%$ versus $0.4 \% ; p=0.18$ ). The multivariate logistic regression identified the following variables as influencing postoperative morbidity: Age $\geq 70$ years (Odds Ratio [OR] 1.99 [95\% CI 1.06 to 3.74], $p=0.033$ ); ASA $3+4$ (OR 2.29 [95\% Confidence Interval (CI) 1.22 to 4.3]; $p=0.010$ ); type of operation (gastropexy) (OR 2.36 [95\% CI 1.27 to 4.37 ]; $p=0.006$ ).

Conclusions In patients undergoing laparoscopic paraesophageal hernia repair age, ASA score, and type of operation significantly influence postoperative morbidity and mortality. Morbidity is substantial among elderly patients and those with co-morbidity, questioning the paradigm for surgery in all patients. The indication for surgery must be carefully balanced against the individual patient's co-morbidities, age, and symptoms, and the potentially life threatening complications.

\section{Introduction}

Laparoscopic paraesophageal hernia (PEH) repair has gained wide acceptance and is a well-established procedure [1,2]. True paraesophageal hernias are rare, accounting for approximately $5 \%$ of all hiatal hernias. These are classified into four groups: type 1, sliding hernias; type 2, true paraesophageal hernias with the gastroesophageal junction remaining in its normal position; type 3 , a combination of types 1 and 2; and type 4, in which the stomach migrates completely into the thoracic cavity (i.e., upside-down stomach), sometimes accompanied by other visceral organs [3].

Until recently, PEH management involved surgical repair irrespective of symptoms [4]. This aggressive strategy was based on reports of life-threatening complications, 
such as bleeding, strangulation, and gastric volvulus and has recently been called into question [5, 6]. Many authors describe the laparoscopic approach as safe and the results as satisfying; nevertheless, outcome is considerably impaired by morbidity, mortality, and recurrence rates of $30 \%, 5 \%$, and $42 \%$, respectively [4, 7-13].

Paraesophageal hernia is diagnosed predominantly among the elderly population, where age-associated co-morbidities are inherent. Although the laparoscopic approach has been shown to be safe, morbidity markedly increases with advanced age and co-morbidity [14]. Data on the influence of age and other predictive factors on morbidity and mortality are scarce.

The aim of the present study was to analyze the influence of age, American Society of Anesthesiologists (ASA) score, body mass index (BMI), type of hernia, and type of operation on postoperative morbidity, mortality, conversion rate, and length of hospital stay.

\section{Patients and methods}

Since 1995 the Swiss Association for Laparoscopic and Thoracoscopic Surgery (SALTS) has prospectively collected data from patients undergoing laparoscopic procedures. Approximately $75 \%$ of all laparoscopic operations performed in Switzerland are entered into the database. For each patient, 130 single items, including basic demographics, ASA score, morbidity, mortality, conversion rate, and length of hospital stay, are recorded on a computerized worksheet. These data sheets are transferred into a database program (Qualicare) by one person qualified to verify the data.

In the present study, all patients of the prospective SALTS database with laparoscopic PEH repairs performed between 1995 and 2006 were analyzed $(n=354)$. Morbidity was defined as intraoperative (i.e., a complication during the surgical procedure, such as bleeding or injury of adjacent organs) or postoperative. Early recurrence was not considered as postoperative morbidity. Postoperative morbidity was further differentiated into local, defined as a complication directly related to surgery-e.g., hematoma or surgical site infection-and general, which included all complications not directly related to surgery, such as pulmonary or cardiac disorders.

The influence of the following variables on morbidity was analyzed: age, ASA score, BMI, type of operation (repair with fundoplication versus repair with gastropexy), and hernia type. Weight and height of patients was noted on the worksheet in increments of $10 \mathrm{~kg}$ and $5 \mathrm{~cm}$, respectively, and BMI was calculated from these approximations. Factors influencing length of hospital stay were also determined.
A receiver operating characteristic (ROC) curve analysis was performed to group the patients according to age in relation to morbidity. Cutoff values between 68 and 70 years showed a good compromise between sensitivity and specificity. Accordingly, patients were grouped according to age $<70$ years and age $\geq 70$ years. A subgroup analysis to assess patients aged $\geq 80$ years was also performed. Results are expressed as mean \pm standard deviation (SD) or median with range. Qualitative data were compared using Fisher's exact test or chi-square test, as appropriate. Quantitative data were compared with the Mann-Whitney $U$-test or, in case of normal distribution, with Student's $t$-test. For the ASA score, patients were grouped into low-risk (ASA $1+2$ ) and high-risk (ASA $3+4)$ collectives. To analyze the influence of single parameters on morbidity, a multivariate stepwise forward regression analysis of the following variables was conducted: age, sex, ASA, BMI, type of operation, and hernia type. Results are shown as odds ratio (OR) with $95 \%$ confidence interval (CI). Statistical analysis was done with SPSS, version 13 (SPSS $®$ Inc, Chicago, IL). Regardless of the statistical tests selected, the level of significance was defined as $p \leq 0.05$.

\section{Results}

The evaluation covered 354 patients with $\mathrm{PEH}$ type 2 $(n=131,37.0 \%)$, type $3(n=90,25.4 \%)$, and type 4 $(n=133,37.6 \%)$. There were 227 women $(64.1 \%)$ and 127 men (35.9\%). Median age was 64 years (range: 23-90 years). In 237 patients $(66.9 \%)$ a hernia repair with fundoplication was performed. In 117 patients (33.1\%) the repair was combined with a gastropexy without any antireflux procedure. Overall morbidity and mortality were $15.3 \%(n=54)$ and $0.8 \%(n=3)$, respectively. In 20 patients $(5.6 \%)$ the operation was converted to open repair with laparotomy.

The basic demographics of the age groups are shown in Table 1. There were 227 patients $<70$ years (median age: 58; range: $23-69$ years) and 127 patients $\geq 70$ (median age: 77; range: 70-90 years). There was a significant difference between the two groups in terms of ASA score, type of operation, and hernia type. Intraoperative morbidity was not influenced by any of the analyzed parameters, with the exception of conversion.

The results of postoperative morbidity between age groups $<70$ and $\geq 70$ with subgroup analysis concerning the type of operation are shown in Table 2.

By subdividing the older age group into those $70-79$ years of age and those $\geq 80$ years, we could show a significantly higher mortality in the oldest patient group $(p<0.001)$ (Table 3). All three patients who died were 
Table 1 Demographics of groups $<70$ and $\geq 70$ years of age

\begin{tabular}{|c|c|c|c|}
\hline & $\begin{array}{l}\text { Age }<70 \\
(n=227) \\
n(\%)\end{array}$ & $\begin{array}{l}\text { Age } \geq 70 \\
(n=127) \\
n(\%)\end{array}$ & $p$ value \\
\hline Sex & & & $<0.001$ \\
\hline Female & $124(54.6)$ & $103(81.1)$ & \\
\hline Male & $103(45.4)$ & 24 (18.9) & \\
\hline $\mathrm{BMI}^{\mathrm{a}}$ & $27.46(19.1-45.4)$ & $26.95(16.9-38.7)$ & 0.09 \\
\hline $\mathrm{ASA}^{\mathrm{b}}$ score & & & $<0.001$ \\
\hline $1+2$ & $184(81.0)$ & $74(58.2)$ & \\
\hline $3+4$ & $43(19.0)$ & $53(41.8)$ & \\
\hline Conversion & $13(5.7)$ & $6(4.7)$ & 0.81 \\
\hline Operation & & & $<0.001$ \\
\hline Fundoplication & $170(74.9)$ & $67(52.8)$ & \\
\hline Gastropexy & $54(25.1)$ & $60(47.2)$ & \\
\hline Hernia type & & & $<0.001$ \\
\hline 2 & $98(43.2)$ & $33(26.0)$ & \\
\hline 3 & $69(30.4)$ & $21(16.5)$ & \\
\hline 4 & $60(26.4)$ & $73(57.5)$ & \\
\hline
\end{tabular}

$B M I$ body mass index; ASA American Society of Anesthesiologists

a Median (range)

b Mean $( \pm \mathrm{SD})$

Table 2 Postoperative morbidity and mortality between age groups $<70$ and $\geq 70$ with subgroup analysis concerning the type of operation

\begin{tabular}{clll}
\hline & $\begin{array}{l}\text { Age }<70 \\
n(\%)\end{array}$ & $\begin{array}{l}\text { Age } \geq 70 \\
n(\%)\end{array}$ & $p$ value \\
\hline All operations $(n=354)$ & $n=227$ & $n=127$ & \\
Overall postoperative morbidity & $23(10.1)$ & $31(24.4)$ & 0.001 \\
General postoperative morbidity & $19(8.4)$ & $24(18.9)$ & 0.006 \\
Local postoperative morbidity & $5(2.2)$ & $12(9.4)$ & 0.004 \\
Mortality & 0 & $3(2.4)$ & 0.045 \\
Fundoplication $(n=237)$ & $n=170$ & $n=67$ & \\
Overall postoperative morbidity & $17(10.0)$ & $8(11.9)$ & 0.65 \\
General postoperative morbidity & $16(9.4)$ & $7(10.4)$ & 0.81 \\
Local postoperative morbidity & $2(1.2)$ & $4(6.0)$ & 0.06 \\
Mortality & 0 & $1(1.5)$ & 0.28 \\
Gastropexy $(n=117)$ & $n=57$ & $n=60$ & \\
Overall postoperative morbidity & $6(10.5)$ & $23(38.8)$ & 0.001 \\
General postoperative morbidity & $3(5.3)$ & $17(28.3)$ & 0.001 \\
Local postoperative morbidity & $3(5.3)$ & $8(13.3)$ & 0.21 \\
Mortality & 0 & $2(3.3)$ & 0.50 \\
\hline
\end{tabular}

$\geq 80$ years old. By subdividing the groups even further into the type of operation performed, the mortality was still significantly higher in the oldest group $(p<0.001$ in the fundoplication group and $p=0.03$ in the gastropexy group). The difference in morbidity in the three age groups was comparable to the results presented in Table 2. There was a statistically significant difference in overall postoperative morbidity $(p<0.001)$ and local postoperative morbidity $(p=0.004)$ but no significant difference in general postoperative morbidity $(p=0.007)$. By subdividing the postoperative morbidity into the type of operations performed, again only the gastropexy group showed a statistically significant difference in overall morbidity $(p=0.002)$ and general morbidity $(p=0.004)$. There was no difference in the local postoperative morbidity in the gastropexy group $(p=0.29)$. There was no significant difference in postoperative overall, general, or local postoperative morbidity in the three age groups of patients treated with fundoplication.

High-risk patients (ASA $3+4$ ) showed significantly higher morbidity than low-risk patients (ASA $1+2$ ), whereas mortality did not differ (Table 4). Body mass index had no significant effect on morbidity or mortality.

Postoperative morbidity differed significantly between types of hernia (type 2: 9.9\%; type 3: $11.1 \%$; type 4: $23.3 \% ; p=0.005)$. Although all three deaths occurred in type 4 hernias, statistical significance was not reached $(p=0.081)$. Conversion was significant for postoperative morbidity ( $42.1 \%$ versus $13.7 \%, p=0.003$ ), as well as for intraoperative morbidity $(31.6 \%$ versus $3.0 \%$; $p<0.001)$. Hospital stay was significantly influenced by age, ASA score, morbidity, conversion, and type of operation (Table 5).

The multivariate stepwise forward regression analysis identified the following variables as significantly influencing postoperative morbidity: age $\geq 70$ years (OR 1.99 [95\% CI 1.06 to 3.74], $p=0.033$ ); ASA $3+4$ (OR 2.29 [95\% CI 1.22 to 4.3 ]; $p=0.010$ ); type of operation (gastropexy) (OR 2.36 [95\% CI 1.27 to 4.37]; $p=0.006$ ). All other variables (sex, BMI, hernia type) had no influence on outcome.

\section{Discussion}

This study shows that morbidity in patients undergoing laparoscopic PEH repair is quite substantial and that age has a significant influence on postoperative morbidity and mortality. Three patients died postoperatively. Unfortunately we were not able to specify the causes of death, for they were not recorded in the database. Postoperative morbidity and mortality were significantly higher in patients older than 70 years of age. These findings are consistent in patients older than 80 years. Postoperative morbidity increased with age in patients undergoing hernia repair with gastropexy. In patients with repair and fundoplication, age had no influence on morbidity. Patients older than 70 years had significantly more frequently a 
Table 3 Postoperative morbidity between age groups $<70$ and $70-79$ and $\geq 80$ with subgroup analysis concerning the type of operation

\begin{tabular}{|c|c|c|c|c|}
\hline & $\begin{array}{l}\text { Age }<70 \\
n(\%)\end{array}$ & $\begin{array}{l}\text { Age } 70-79 \\
n(\%)\end{array}$ & $\begin{array}{l}\text { Age } \geq 80 \\
n(\%)\end{array}$ & $p$ value \\
\hline All operations $(n=354)$ & $n=227$ & $n=90$ & $n=37$ & \\
\hline Overall postoperative morbidity & $23(10.1)$ & $19(21.1)$ & $12(32.4)$ & $<0.001$ \\
\hline General postoperative morbidity & $19(8.4)$ & $15(16.7)$ & $9(24.3)$ & 0.007 \\
\hline Local postoperative morbidity & $5(2.2)$ & $7(7.8)$ & $5(13.5)$ & 0.004 \\
\hline Mortality & 0 & 0 & $3(8.1)$ & $<0.001$ \\
\hline Fundoplication $(n=237)$ & $n=170$ & $n=56$ & $n=11$ & \\
\hline Overall postoperative morbidity & $17(10.0)$ & $7(12.5)$ & $1(9.1)$ & 0.86 \\
\hline General postoperative morbidity & $16(9.4)$ & $6(10.7)$ & $1(9.1)$ & 0.96 \\
\hline Local postoperative morbidity & $2(1.2)$ & $3(5.4)$ & $1(9.1)$ & 0.08 \\
\hline Mortality & 0 & 0 & $1(9.1)$ & $<0.001$ \\
\hline Gastropexy $(n=117)$ & $n=57$ & $n=34$ & $n=26$ & \\
\hline Overall postoperative morbidity & $6(10.5)$ & $12(35.3)$ & $11(42.3)$ & 0.002 \\
\hline General postoperative morbidity & $3(5.3)$ & $9(26.5)$ & $8(30.8)$ & 0.004 \\
\hline Local postoperative morbidity & $3(5.3)$ & $4(11.8)$ & $4(15.4)$ & 0.29 \\
\hline Mortality & 0 & 0 & $2(7.7)$ & 0.03 \\
\hline
\end{tabular}

Table 4 Postoperative morbidity between high and low risk groups with subgroup analysis concerning the type of operation

\begin{tabular}{clll}
\hline & ASA score & ASA score & $p$ value \\
& $1+2$ & $3+4$ & \\
& $n(\%)$ & $n(\%)$ & \\
\hline All operations $(n=354)$ & $n=258$ & $n=96$ & \\
Overall postoperative morbidity & $29(11.2)$ & $25(26.0)$ & 0.001 \\
General postoperative morbidity & $24(9.3)$ & $19(19.8)$ & 0.010 \\
Local postoperative morbidity & $7(2.7)$ & $10(10.4)$ & 0.005 \\
Mortality & $1(0.4)$ & $2(2.1)$ & 0.180 \\
Fundoplication $(n=237)$ & $n=177$ & $n=60$ & \\
Overall postoperative morbidity & $15(8.5)$ & $10(16.7)$ & 0.09 \\
General postoperative morbidity & $14(7.9)$ & $9(15)$ & 0.13 \\
Local postoperative morbidity & $2(1.1)$ & $4(6.7)$ & 0.04 \\
Mortality & 0 & $1(1.7)$ & 0.25 \\
Gastropexy $(n=117)$ & $n=81$ & $n=36$ & \\
Overall postoperative morbidity & $14(17.3)$ & $15(41.7)$ & 0.010 \\
General postoperative morbidity & $10(12.3)$ & $10(27.8)$ & 0.06 \\
Local postoperative morbidity & $5(6.2)$ & $6(16.7)$ & 0.09 \\
Mortality & $1(1.2)$ & $1(2.8)$ & 0.52 \\
\hline
\end{tabular}

gastropexy, whereas among younger patients a fundoplication was performed more often. Reasons for this may include a belief that gastropexy is less invasive than fundoplication and therefore more suitable for elderly patients. However, our results do not support this hypothesis, as fundoplication patients had no increasing morbidity with advancing age, in contrast to patients undergoing gastropexy. There could also be other factors that influence the choice of operation type, both preopedratively and
Table 5 Influence of the different variable s on length of hospital stay

\begin{tabular}{llll}
\hline & $\begin{array}{l}\text { Median } \\
\text { (range) }\end{array}$ & $\begin{array}{l}\text { Median } \\
\text { (range) }\end{array}$ & $p$ value \\
\hline Age & $<70$ years & $\geq 70$ years & \\
& $6.0(2-35)$ & $9.0(3-42)$ & $<0.001$ \\
ASA score & ASA 1 + 2 & ASA 3 + 4 & \\
& $6.5(2-36)$ & $8.0(3-42)$ & $<0.001$ \\
Operation type & Fundoplication & Gastropexy & \\
& $6.0(2-42)$ & $8.0(3-36)$ & $<0.001$ \\
Morbidity/conversion rate & No & Yes & \\
$\quad \begin{array}{l}\text { Postoperative } \\
\text { morbidity }\end{array}$ & $6.0(2-21)$ & $13.0(5-42)$ & $<0.001$ \\
$\quad \begin{array}{lll}\text { Local morbidity } \\
\text { General morbidity }\end{array}$ & $7.0(2-36)$ & $18.0(9-42)$ & $<0.001$ \\
Conversion & $6.0(2-35)$ & $13.0(5-42)$ & $<0.001$ \\
\hline
\end{tabular}

intraoperatively, that are not documented in the database and that could be influencing the difference between the operations. It is therefore impossible to conclude that fundoplication should be preferred over gastropexy. Fundoplication allows a good fixation of the fundus and gastroesophageal junction to the crura, thus preventing recurrence of the hiatal hernia $[1,15,16]$. Additionally, dissection of the hiatus to reduce the hernia results in high rate of postoperative reflux, which can pre-emptively be treated with a fundoplication [17].

Complication and mortality rates in this study are comparable to those reported in the literature [7, 10, 18]. Age over 70 years was found to be a significant factor 
influencing the outcome, with an odds ratio of 2.0. To our knowledge, only one other study has assessed the influence of age on morbidity in paraesophageal hernia repair [14]. These authors found no significant difference between three age groups of patients ( $<65$ years, $65-74$ years, $>75$ years). Although the total complication rate in the oldest group was $27 \%$, the authors concluded that laparoscopic PEH repair is safe in elderly patients. As Dahlberg et al. stated in 2001, laparoscopic hernia repair is a challenging operation with significant morbidity and mortality [19]. This statement is still valid, as complication rates of up to $24 \%$ were demonstrated in recent series [7, 20]. Furthermore, up to $25 \%$ of elderly patients may experience delirium during hospitalization [21]. Over $50 \%$ of patients experiencing an episode of in-hospital delirium will not be able to live independently in the community two years later [22].

High-risk patients (ASA $3+4$ ) showed significantly higher morbidity, although mortality rates did not significantly differ. In addition, the ASA scores were higher in the older population. The odds ratio for postoperative complications in patients with ASA scores $3+4$ was 2.3. Therefore age and ASA score act synergistically. Elderly patients with little co-morbidity may be candidates for surgery, whereas the indication for surgery in elderly patients with ASA score of 3 or more should be carefully considered.

Type 4 hernia is associated with the highest morbidity and mortality. This is not surprising, as these hernias are the most challenging to reduce and the hiatal defect is the largest. The distribution of hernia type between age groups differed significantly. Patients older than 70 years had type 4 hernias more often. However, type of hernia was not a significant factor for postoperative morbidity in the multivariate regression analysis.

Length of hospital stay was another factor significantly influenced by age, ASA score, morbidity, conversion, and type of operation. Elderly patients and patients with co-morbidity stayed 2 days longer than young and low-risk patients. Postoperative complications or conversion doubled duration of hospital stay. A median stay of 2 days is reported generally in the literature [14, 18, 23, 24]. Our patients remained in the hospital longer. System-related reasons and social factors such as delayed transfer to rehabilitation institutions may explain this finding.

Minimally invasive PEH repair has been shown to be safe and effective and has therefore gained rapid acceptance $[3,17]$. Based on reports of high complication rates with conservative management, surgery has been recommended for all patients $[4,5,18]$. This dogma has been challenged by Stylopoulos et al., who were able to show that watchful waiting is a reasonable alternative to surgery [6]. Allen et al. observed 23 patients with medical treatment for a follow-up median of 78 months, and only 4 patients (17\%) developed progressive symptoms [25]. Morbidity and recurrence rates of up to $25 \%$ and $30 \%$, respectively, are certainly not negligible $[7,10,12,14]$. Nevertheless, laparoscopic repair has been associated with good postoperative symptom relief [2, 26, 27].

To our knowledge, this study is the largest assessing predictive factors on morbidity and mortality after laparoscopic PEH repair. Some limitations merit mentioning. The SALTS database contained no information about preoperative symptoms, the indications for the operation and subjective outcome postoperatively, or the specific type of fundoplication performed. Also, the causes of complications cannot be identified from the database, and this represents a major limitation. The database was developed to analyze all laparoscopic operations and is thus quite general. Additionally, the present study does not analyze the recurrence rate, as there was no follow-up after discharge.

\section{Conclusions}

Age, ASA score, and type of operation significantly influence postoperative morbidity and mortality in patients undergoing laparoscopic PEH repair. In patients undergoing fundoplication, age had no influence on outcome. The indication for surgery must be carefully balanced against the individual patient's co-morbidities, age, and symptoms, and the potentially life-threatening complications.

\section{References}

1. Gantert WA, Patti MG, Arcerito M et al (1998) Laparoscopic repair of paraesophageal hiatal hernias. J Am Coll Surg 186:428432 discussion 432-423

2. Ferri LE, Feldman LS, Stanbridge D et al (2005) Should laparoscopic paraesophageal hernia repair be abandoned in favour of the open approach? Surg Endosc 19:4-8

3. Draaisma WA, Gooszen HG, Tournoij E et al (2005) Controversies in paraesophageal hernia repair: a review of literature. Surg Endosc 19:1300-1308

4. Mehta S, Boddy A, Rhodes M (2006) Review of outcome after laparoscopic paraesophageal hiatal hernia repair. Surg Laparosc Endosc Percutan Tech 16:301-306

5. Skinner DB, Belsey RH (1967) Surgical management of esophageal reflux and hiatus hernia. Long-term results with 1,030 patients. J Thorac Cardiovasc Surg 53:33-54

6. Stylopoulos N, Gazelle GS, Rattner DW (2002) Paraesophageal hernias: operation or observation? Ann Surg 236:492-500; discussion 500-501

7. Parameswaran R, Ali A, Velmurugan S et al (2006) Laparoscopic repair of large paraesophageal hiatus hernia: quality of life and durability. Surg Endosc 20:1221-1224

8. Targarona EM, Novell J, Vela S et al (2004) Mid term analysis of safety and quality of life after the laparoscopic repair of paraesophageal hiatal hernia. Surg Endosc 18:1045-1050 
9. Zaninotto G, Portale G, Costantini M et al (2007) Objective follow-up after laparoscopic repair of large type III hiatal hernia. Assessment of safety and durability. World J Surg 31:2177-2183

10. Pierre AF, Luketich JD, Fernando HC et al (2002) Results of laparoscopic repair of giant paraesophageal hernias: 200 consecutive patients. Ann Thorac Surg 74:1909-1915; discussion 1915-1906

11. Mattar SG, Bowers SP, Galloway KD et al (2002) Long-term outcome of laparoscopic repair of paraesophageal hernia. Surg Endosc 16:745-749

12. Wu JS, Dunnegan DL, Soper NJ (1999) Clinical and radiologic assessment of laparoscopic paraesophageal hernia repair. Surg Endosc 13:497-502

13. Hashemi M, Peters JH, DeMeester TR et al (2000) Laparoscopic repair of large type III hiatal hernia: objective followup reveals high recurrence rate. J Am Coll Surg 190:553-560 discussion 560-551

14. Gangopadhyay N, Perrone JM, Soper NJ et al (2006) Outcomes of laparoscopic pa24raesophageal hernia repair in elderly and high-risk patients. Surgery 140:491-498 discussion 498-499

15. Edye MB, Canin-Endres J, Gattorno F et al (1998) Durability of laparoscopic repair of paraesophageal hernia. Ann Surg 228: $528-535$

16. Casabella F, Sinanan M, Horgan S et al (1996) Systematic use of gastric fundoplication in laparoscopic repair of paraesophageal hernias. Am J Surg 171:485-489

17. Lal DR, Pellegrini CA, Oelschlager BK (2005) Laparoscopic repair of paraesophageal hernia. Surg Clin North Am 85:105-118

18. Leeder PC, Smith G, Dehn TC (2003) Laparoscopic management of large paraesophageal hiatal hernia. Surg Endosc 17:1372-1375
19. Dahlberg PS, Deschamps C, Miller DL et al (2001) Laparoscopic repair of large paraesophageal hiatal hernia. Ann Thorac Surg 72:1125-1129

20. Oelschlager BK, Pellegrini CA, Hunter J et al (2006) Biologic prosthesis reduces recurrence after laparoscopic paraesophageal hernia repair: a multicenter, prospective, randomized trial. Ann Surg 244:481-490

21. Brown TM, Boyle MF (2002) Delirium. BMJ 325:644-647

22. Francis J, Kapoor WN (1992) Prognosis after hospital discharge of older medical patients with delirium. J Am Geriatr Soc 40:601-606

23. Andujar JJ, Papasavas PK, Birdas T et al (2004) Laparoscopic repair of large paraesophageal hernia is associated with a low incidence of recurrence and reoperation. Surg Endosc 18:444447

24. Luketich JD, Raja S, Fernando HC et al (2000) Laparoscopic repair of giant paraesophageal hernia: 100 consecutive cases. Ann Surg 232:608-618

25. Allen MS, Trastek VF, Deschamps C et al (1993) Intrathoracic stomach. Presentation and results of operation. J Thorac Cardiovasc Surg 105:253-258; discussion 258-259

26. Diaz S, Brunt LM, Klingensmith ME et al (2003) Laparoscopic paraesophageal hernia repair, a challenging operation: mediumterm outcome of 116 patients. J Gastrointest Surg 7:59-66; discussion $66-57$

27. Velanovich V, Karmy-Jones R (2001) Surgical management of paraesophageal hernias: outcome and quality of life analysis. Dig Surg 18:432-437; discussion 437-438 